\title{
An Investigation on the Deformation Heating in Billet and Die During Equal-Channel Angular Pressing and High-Pressure Torsion
}

\author{
Javad Shahbazi Karamia * \\ ${ }^{a}$ Faculty of Mechanical Engineering, Shahid Rajaee Teacher Training University, Tehran, Iran
}

Received: May 16, 2015; Revised: August 31, 2015; Accepted: March 11, 2016

\begin{abstract}
This work aims to investigate the temperature rise in Aluminum alloy 6061 due to deformation heating in equal channel angular pressing (ECAP) and high-pressure torsion (HPT) processes using finite element method. The roles of various parameters are investigated and the heating of ECAP die due to billet deformation is included in the simulations. The results show that while the work-piece moves in the exit channel, the generated heat is transferred to die via conduction and therefore the temperature isosurfaces in die are extended in the direction of inlet and exit channels. The dependency of maximum work-piece temperature to velocity is more than its dependency to friction. Increasing the plunger velocity increases the difference between maximum and minimum temperatures. Additionally, the maximum work-piece temperature is attained at the deformation zone. The temperature rise in HPT is less than ECAP due to the small size of the HPT work-piece compared to ECAP. Not only the work-piece size, but also the good heat conduction of aluminum makes the temperature distribution roughly uniform in HPT.
\end{abstract}

Keywords: Deformation heating, Severe plastic deformation, High-pressure torsion, equal-channel angular pressing, Finite element

\section{Introduction:}

Equal-channel angular pressing (ECAP) and High-pressure torsion are widely used to refine grain structure and improve the mechanical properties of various materials. ECAP and HPT are performed under high applied pressures and at low temperatures ${ }^{1,2}$. In the ECAP process, a well-lubricated billet is pressed in a die comprising two channels intersecting at a constant angle. The material is then subjected to shear deformation ${ }^{3,4}$. Since the cross section remains constant, repetitive pressing is possible to impose large cumulative strains. However, the imposed cumulative strain will depend on the material, temperature, speed and geometry of the die. Multiple ECAP processing makes it possible to rotate the billet around its central axis between the passes. Different routes are then created that has been classified into four routes: (I) Route $\mathrm{A}$, no rotation around central axis (II) Route $\mathrm{B}_{\mathrm{A}}$, rotating $90^{\circ}$ in opposite directions, (II) Route $\mathrm{B}_{\mathrm{c}}$, rotating $90^{\circ}$ in the same direction and (IV) Route C, rotating $180^{\circ}$. In HPT the billets are subjected to a compressive force and concurrent torsional straining in which the deformation is continuous ${ }^{6}$.

ECAP and HPT are considered useful to strengthen materials by inducing large plastic deformation in one deformation step. Various studies have been performed to show the importance of these methods in improving the properties of different materials. Significant improvement in tensile strength ${ }^{7}$, fatigue resistance ${ }^{8}$, impact toughness ${ }^{9}$,

*e-mail: J.Shahbazi@SRTTU.edu wear resistance ${ }^{10,11}$, corrosion behavior ${ }^{12,13}$ superplasticity ${ }^{14,15}$, formability ${ }^{16}$, etc were observed using this method.

ECAP processing is usually carried out at room temperature and homogeneous grain refinement is expected throughout the sample. Some brittle materials are processed at high temperature and the mechanism of grain refinement may lead to heterogeneous grain structure with multi-modal grain size distribution ${ }^{17}$. However, new methods are proposed to develop homogeneous grain size distribution in the materials ${ }^{18,19}$. In addition, the material processed by ECAP may present mechanical anisotropy, where the stress-strain behavior may vary with respect to the orientation of processing by ECAP $^{20-23}$. To analyze the deformation behavior and predict the mechanical anisotropy in the samples, finite element method (FEM) has been widely used by some researchers ${ }^{24-28}$. In these simulations, isothermal condition was assumed while in an experiment a temperature rise of $73^{\circ}$ was recorded ${ }^{29}$. This temperature rise in the sample may affect the grain size and homogeneous grain refinement ${ }^{30,31}$. Some analytical models are developed to predict the average temperature rise in $\mathrm{ECAP}^{32}$. However, FEM may predict the temperature rise in various points of the billet ${ }^{33-35}$. Similarly, FEM could be successfully used to predict the induced strain, damage and temperature rise in $\mathrm{HPT}^{36}$.

This work aims to investigate the temperature rise due to deformation heating in ECAP and HPT processes using 3D-FEM. The roles of various parameters are investigated and the heating of die due to the work-piece deformation is included in the simulations. 


\section{Finite element model}

Three-dimensional simulations of ECAP and HPT were performed using the DEFORM 3D 10.2 software. General simulation conditions for ECAP and HPT are summarised in Table 1. Material properties are mostly selected from library of the software while the friction data are available elsewhere ${ }^{37} .30000$ and 8000 three-dimensional four node tetrahedron (linear tetrahedron) elements were used in the simulations of ECAP and HPT, respectively.

$\rho C_{p}\left(\frac{\partial T}{\partial t}+\boldsymbol{u} \cdot \nabla T\right)=\nabla \cdot(k \nabla T)+Q+W$

In this transient thermal equation, $\rho \mathrm{C}_{\mathrm{p}}$ is volumetric heat capacity, $\mathrm{u}$ is displacement vector, $\mathrm{k}$ is thermal conductivity, $\mathrm{Q}$ is external heating sources, and $\mathrm{W}$ is heating due to deformation which in turn is a function of stress variations inside the billet and contact friction. In rate form one can obtain:

$$
\begin{aligned}
& \dot{W}_{\text {deformation }}=\eta \bar{\sigma} \dot{\bar{\varepsilon}} \\
& \dot{W}_{\text {friction }}=F V
\end{aligned}
$$

In these equations, $\eta$ is the thermal efficiency (between 0.8-0.9), $\bar{\sigma}$ and $\dot{\bar{\varepsilon}}$ are effective stress and strain rate, respectively. In addition, $\mathrm{F}$ is friction force and $\mathrm{V}$ is relative velocity between sample and die. For F:

$$
F=m \tau \cdot \frac{2}{\pi} \cdot \tan ^{-1}\left(\frac{v}{\alpha}\right)
$$

Where $\mathrm{m}$ is shear factor, $\tau$ is shear strength, $\mathrm{v}$ is relative velocity between billet and die, and $\alpha$ is the value of relative sliding velocity below which sticking occurs.

The simulations of HPT assumed sticking conditions between the work-piece and the anvils on top and bottom surfaces and no slippage was allowed. Simulations considered rigid die and punch while thermal analysis was coupled with the deformation analysis. The mesh independency of the results was checked and finally a reasonable number of elements were selected in the simulations to attain relatively accurate and computationally efficient results.

\section{Results and discussion}

\subsection{ECAP}

\subsubsection{Temperature contours in work-piece and die}

For validation purpose, the temperature rise during ECAP for AA-1100 using a plunger speed of $18 \mathrm{~mm} / \mathrm{s}$ was modeled. The results showed reasonable agreement with the measured and calculated data for temperature rise in pure $\mathrm{Al}$. In this work, a temperature rise of $39^{\circ} \mathrm{C}$ was observed while about $17.8^{\circ} \mathrm{C}$ temperature rise was calculated ${ }^{38}$ and about $29^{\circ} \mathrm{C}$ temperature rise was measured ${ }^{29}$ using $\mathrm{V}=18 \mathrm{~mm} / \mathrm{s}$. The difference between the simulated values with calculated and measured values can be related to difference in die parameters, experimental/numerical errors, simplifications, and estimating material properties.

Fig. 1 shows the isosurfaces of temperature in the work-piece after ECAP. As shown in this figure the highest temperature is attained in the vicinity of shear line and deformation zone of the work-piece. This work shows the temperature change not only in the work-piece, but also for the ECAP die. The temperature isosurfaces in the die show temperature rise where the channel is bent. It can be seen in Fig. 1 and Fig. 2 that temperature contours are extended towards the exit channel that originates from the work-piece displacement within the die. While the work-piece moves in the exit channel, the generated heat is transferred to die via conduction and therefore the temperature isosurfaces in die are extended in the direction of inlet and exit channels. The difference in the temperature rise in different parts of the work-piece has several reasons. First, during the deformation, heat transfers from the deformed part to the un-deformed part of the work-piece that makes the later to be deformed at higher temperature and causes more temperature rise in those parts ${ }^{33}$. Second, die temperature increases by the deformed part, and then the undeformed part is deformed in a pre-heated die that causes less heat loss and more temperature rise ${ }^{33}$.

Table 1: Simulation conditions for ECAP and HPT

\section{ECAP}

Work-piece material

Die material

Initial temperature

Work-piece height

Work-piece radius

$\varnothing \quad 90^{\circ}$

$\psi \quad 20^{\circ}$

Plunger velocity $\quad 0.5,1,2 \mathrm{~mm} / \mathrm{s}$

Friction factor

AA-6061-JC
$\mathrm{H} 13$
$20^{\circ} \mathrm{C}$
$60 \mathrm{~mm}$
$5 \mathrm{~mm}$

$$
0,0.19,0.3
$$

Billet thermal conductivity (Both ECAP and HPT) Billet volumetric heat capacity (Both ECAP and HPT) Die thermal conductivity (Both ECAP and HPT) Die volumetric heat capacity (Both ECAP and HPT) Thermal contact conductance per unit area (Both ECAP and HPT)

\section{HPT}

Work-piece material

Die material

Initial temperature

Work-piece height

Work-piece radius

AA-6061-JC
$\mathrm{H} 13$
$20^{\circ} \mathrm{C}$
$1.2 \mathrm{~mm}$
$5 \mathrm{~mm}$

Axial pressure $\quad 1 \mathrm{GPa}$

Angular velocity $\quad 0.1 \mathrm{rad} / \mathrm{s}$

Friction factor $\quad 0.3,0.45$ 


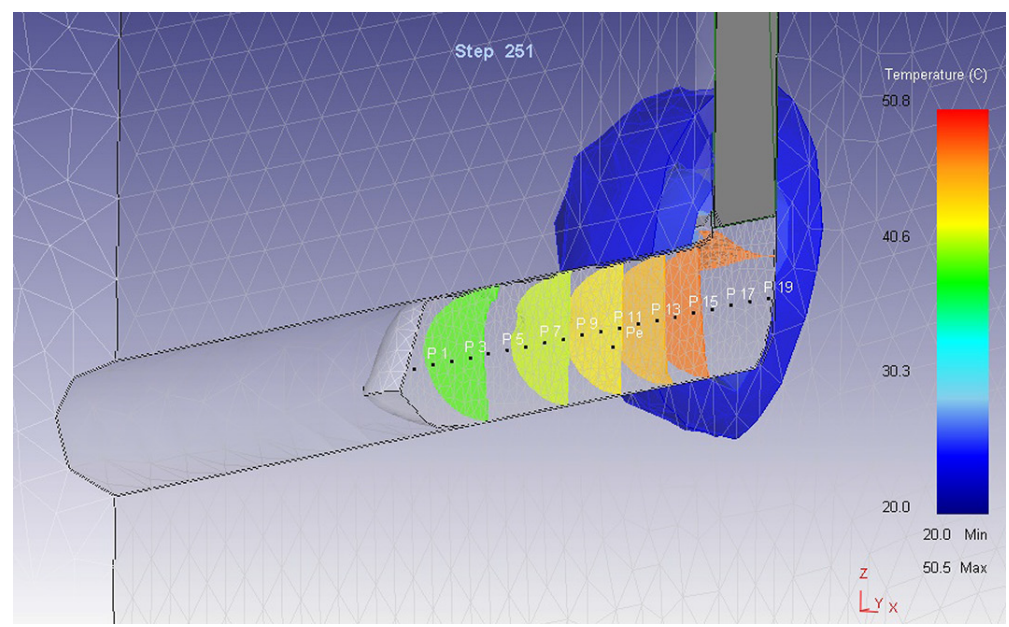

Fig.1: Temperature isosurfaces after ECAP when punch stops

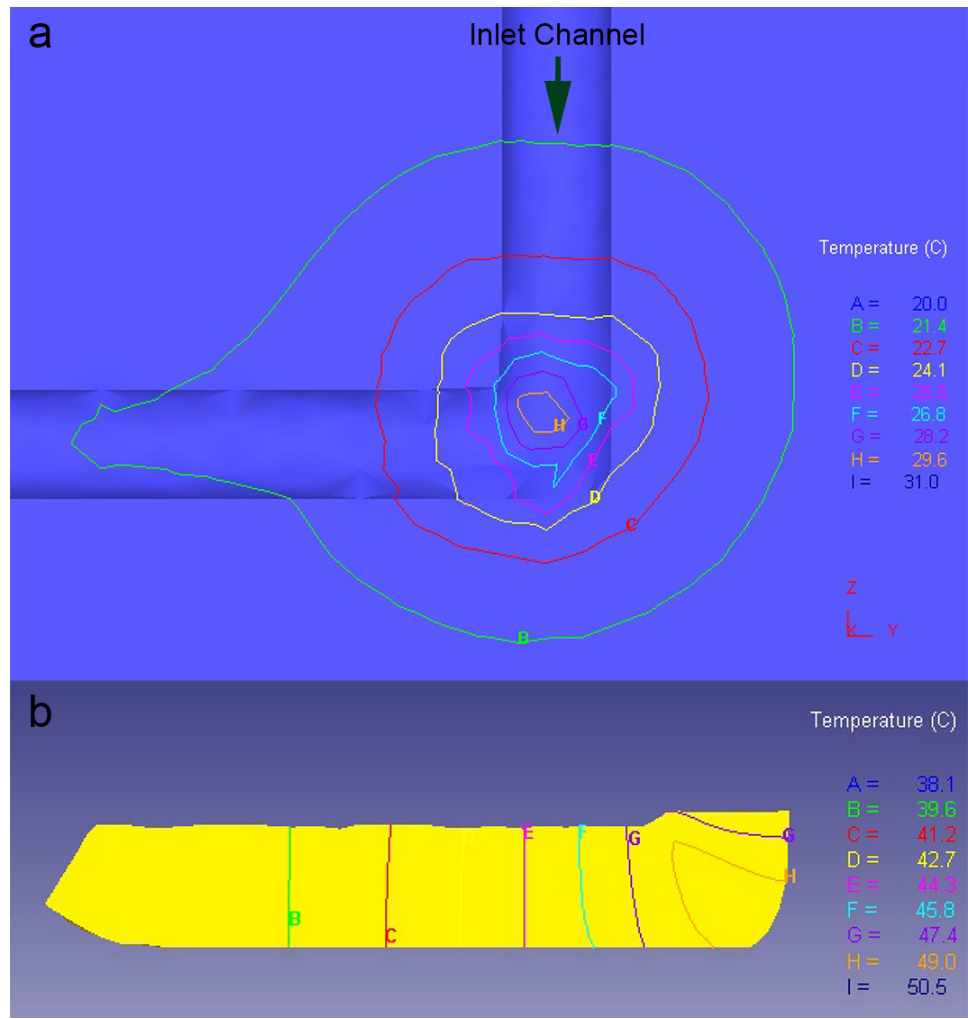

Fig.2: Temperature contours on (a) die, (b) billet when punch stops

\subsubsection{Maximum work-piece and die temperatures}

Fig. 3 shows the maximum work-piece temperature after ECAP. The maximum work-piece temperature is shown as a function of velocity and friction. It is shown that the dependency of maximum work-piece temperature to velocity is more than its dependency to friction. While increasing the friction factor from 0 to 0.3 increases the maximum work-piece temperature only $8^{\circ} \mathrm{C}$, increasing the plunger velocity from 0.5 to 2 increases the maximum work-piece temperature $49^{\circ} \mathrm{C}$ in average.
Fig. 4 shows the maximum die temperature after ECAP. The maximum die temperature is shown as a function of velocity and friction. The dependency of maximum die temperature to velocity is more than its dependency to friction alike maximum work-piece temperature. Nonetheless, the rate of variations are lower in die, e.g. increasing the friction factor from 0 to 0.3 increases the maximum die temperature $7^{\circ} \mathrm{C}$ and increasing the plunger velocity from 0.5 to 2 increases the maximum die temperature $18^{\circ} \mathrm{C}$ in average. This shows that the maximum work-piece temperature is more dependent to velocity variation than the maximum die temperature. 


\subsubsection{Effect of velocity and friction on temperature distribution}

Fig.5. shows the temperature distribution in the centre line of the work-piece (points P1 to P20 shown in Fig.1) for frictionless condition. As mentioned in the previous section, the dependency of maximum work-piece temperature to velocity is more than its dependency to friction. Fig. 5 shows that not only the maximum work-piece temperature, but also the temperature distribution is dependent to velocity. Increasing the plunger velocity increases the difference between maximum and minimum temperatures. Additionally, the maximum work-piece temperature is attained at the deformation zone.

Fig. 6 shows the temperature distribution in the centre line of the work-piece as a function of friction. Increasing the plunger velocity increases the maximum work-piece temperature and the difference between maximum and minimum temperatures in all conditions. It is also interesting to note to the temperature history in different points as shown elsewhere ${ }^{39}$. In figure 7 , one can see that temperature varies sharply in the beginning of the deformation while it is directly dependent to the punch speed.

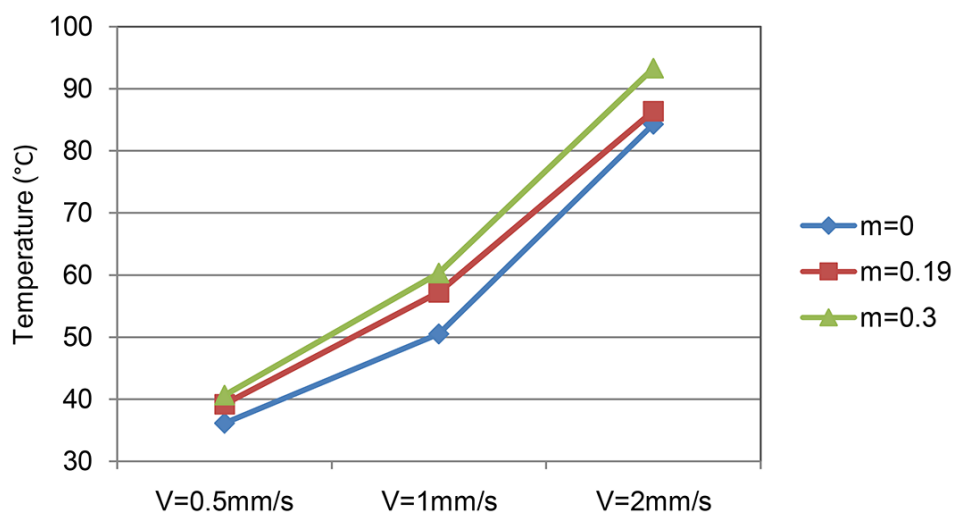

Fig.3: Maximum work-piece temperature as a function of velocity and friction (immediately after end of the process)

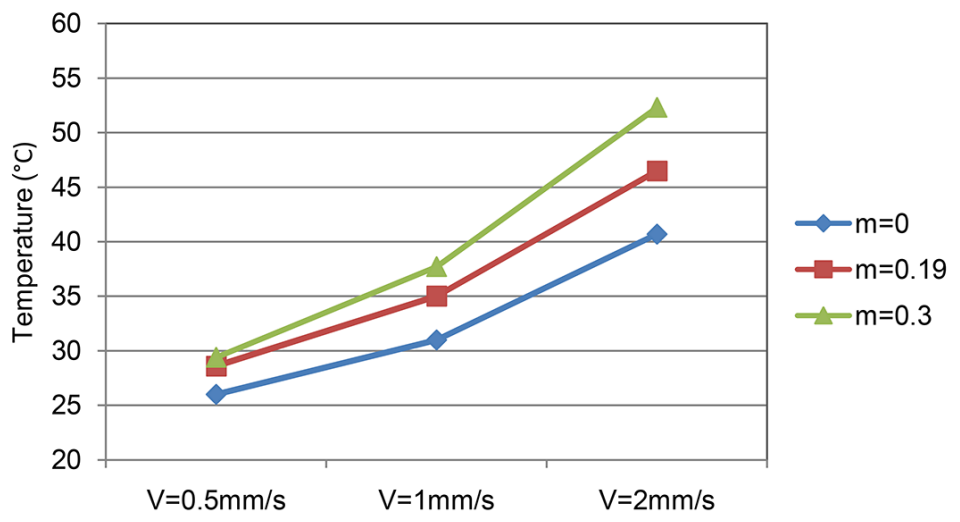

Fig.4: Maximum die temperature as a function of velocity and friction (immediately after end of the process)

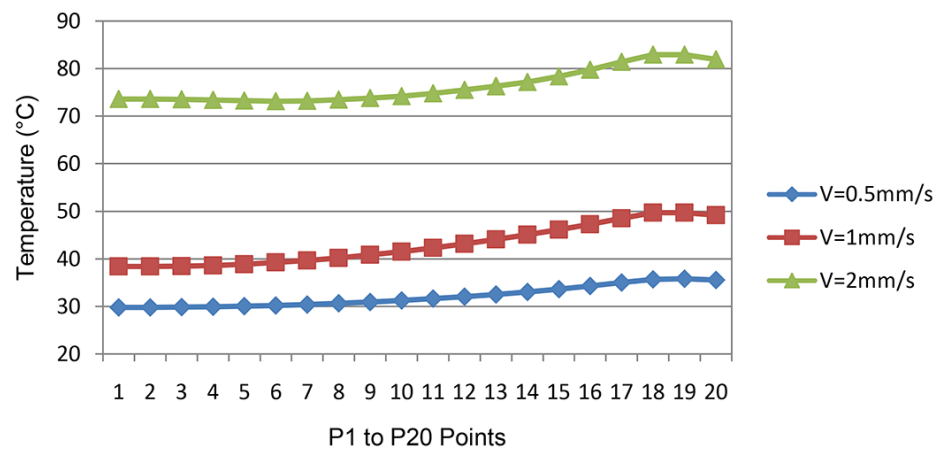

Fig.5: Temperature distribution in the centre line of the work-piece in frictionless condition (immediately after end of the process) 

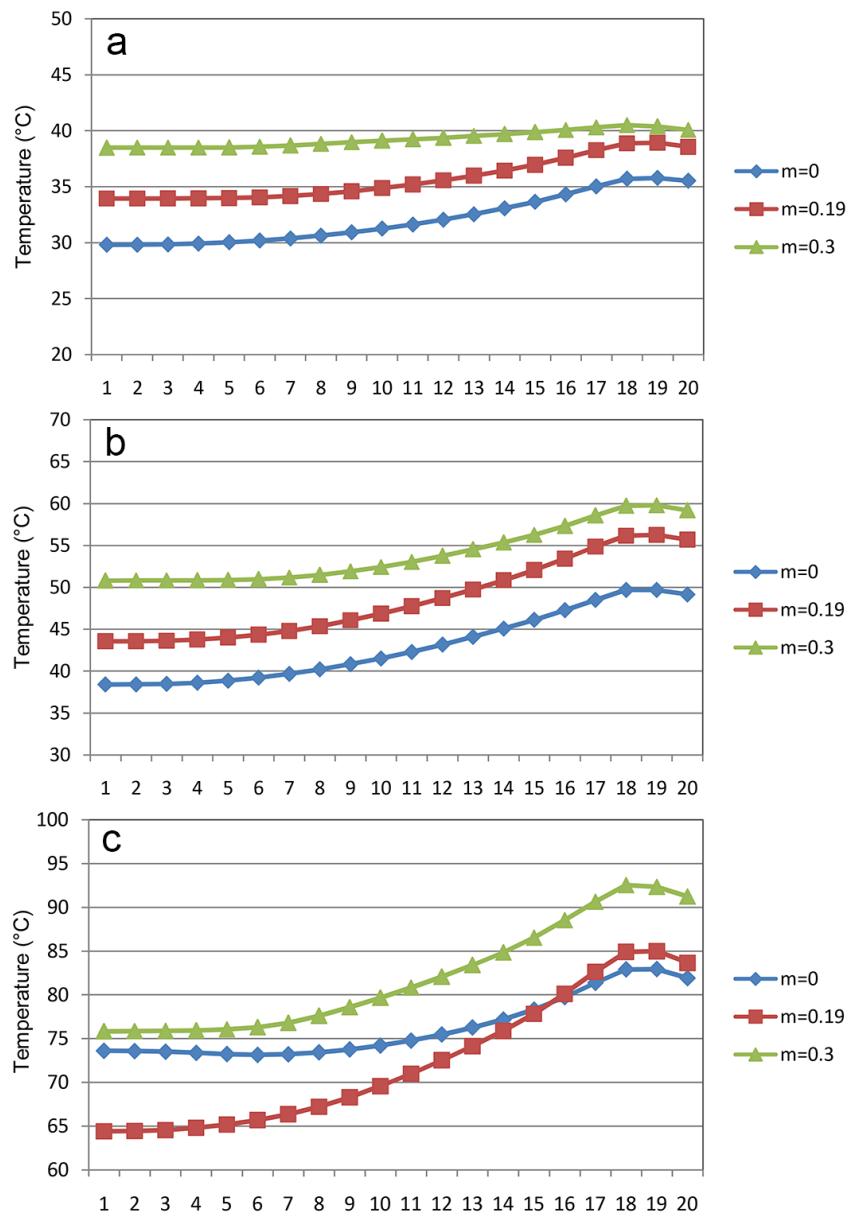

Fig.6: Temperature distribution in the centre line of the work-piece as a function of friction (a) V=0.5mm/s, (b) V=1 mm/s, (c) V=2mm/s at the end of the process

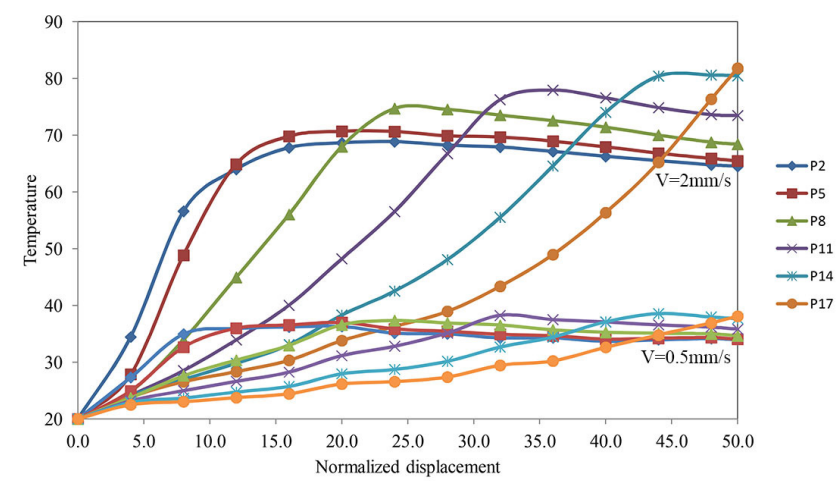

Figure 7: Temperature history versus normalized displacement in different material points for $\mathrm{m}=0.19$

\subsection{HPT}

\subsubsection{Temperature distribution in HPT}

Fig. 8 shows the work-piece temperature after two HPT turns. As shown in this figure the variation of temperature is narrow due to the small size of the work-piece. Not only the work-piece size, but also the good heat conduction of aluminium makes the temperature distribution uniform.
The temperature rise during HPT in the earlier report of Pereira et al. ${ }^{40}$ was reported about $15^{\circ} \mathrm{C}$ with a normal pressure of $940 \mathrm{Mpa}$, a rotation speed of $0.1 \mathrm{rad} / \mathrm{s}$ for a titanium sample after two turns. However, in this work the temperature rise was about $7^{\circ} \mathrm{C}$. Although the main simulation conditions are identical, variation in billet size, friction and processed material are the major reasons for this difference. 


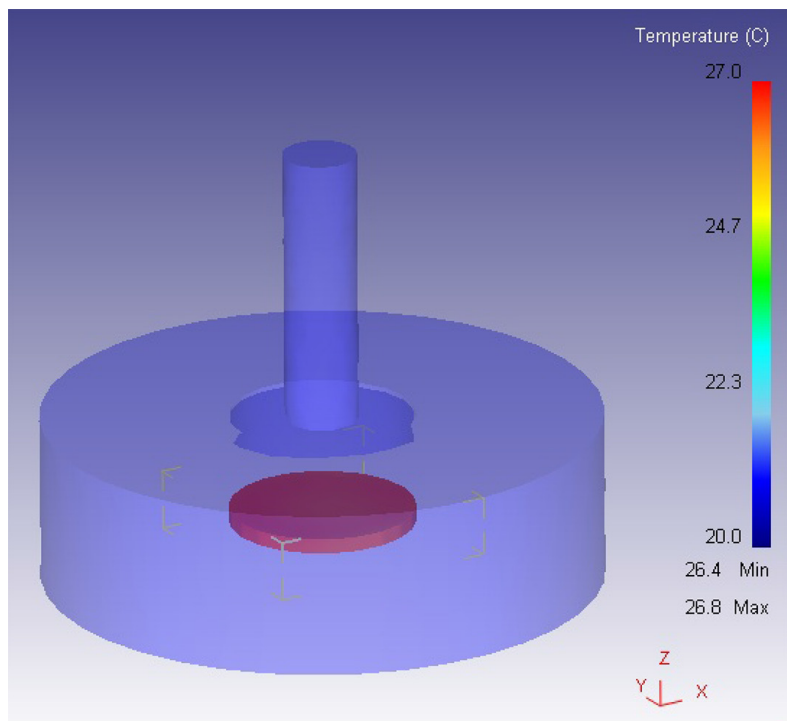

Fig.8: Temperature distribution after HPT

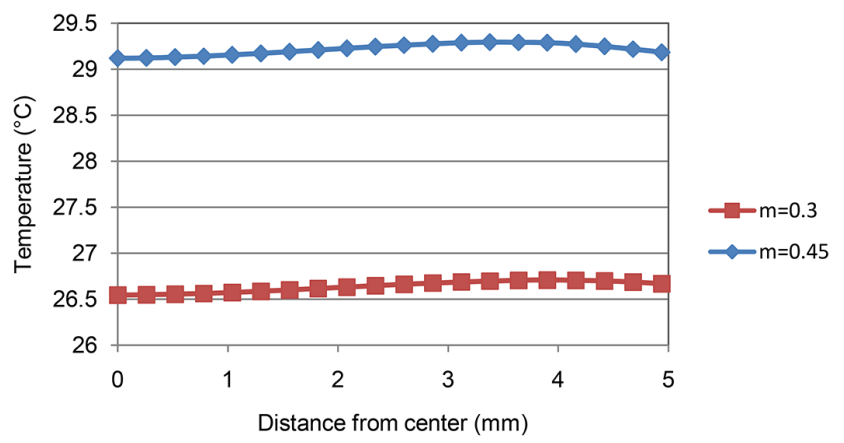

Fig.9: Temperature distribution in radial direction for HPT processed work-piece as a function of friction at the end of the process

The temperature distribution in the centreline of the work-piece is shown in fig. 9. Two friction factors are considered in the simulations. As shown in this figure the temperature rise in HPT is less than ECAP due to the small size of the HPT work-piece compared to ECAP. Nonetheless, increasing the friction factor increases the generated heat during this process. Although the temperature distribution appears uniform, the maximum temperature is attained around $\mathrm{r}=4 \mathrm{~mm}$.

\section{Conclusions:}

This work investigates the temperature rise due to the deformation heating in ECAP and HPT using finite element method. The results show that while the work-piece moves in

\section{References:}

1. Valiev RZ, Langdon TG. Principles of equal-channel angular pressing as a processing tool for grain refinement. Progress in Materials Science. 2006;51(7):881-981. http://dx.doi. org/10.1016/j.pmatsci.2006.02.003.

2. Loucif A, Figueiredo RB, Baudin T, Brisset F, Langdon TG. Microstructural evolution in an Al-6061 alloy processed by the exit channel in ECAP, the generated heat is transferred to die via conduction and therefore the temperature isosurfaces in die are extended in the direction of inlet and exit channels.

It is shown that the dependency of maximum ECAP work-piece temperature to velocity is more than its dependency to friction. Increasing the plunger velocity increases the difference between maximum and minimum temperatures. Additionally, the maximum work-piece temperature is attained at the deformation zone.

The temperature rise in HPT is less than ECAP due to the small size of the HPT work-piece compared to ECAP. Not only the work-piece size, but also the good heat conduction of aluminium makes the temperature distribution roughly uniform in HPT.

high-pressure torsion. Materials Science and Engineering: $A$. 2010;527(18-19): 4864-4869. doi:10.1016/j.msea.2010.04.027

3. Segal VM. Materials processing by simple shear. Materials Science and Engineering: A. 1995;197(2):157-164. doi:10.1016/09215093(95)09705-8

4. Segal VM, Eznikov VI, Drobyshevskiy AE, Kopylov VI. Plastic working of metals by simple shear. Russia Mettalurgy. 1981;1:99-105. 
5. Nakashima K, Horita Z, Nemoto M, Langdon TG. Development of a multi-pass facility for equal-channel angular pressing to high total strains Materials Science and Engineering: A. 2000;281(1-2):82-87. doi:10.1016/S0921-5093(99)00744-3

6. Zhilyaev AP, Langdon TG. Using high-pressure torsion for metal processing: Fundamentals and applications. Progress in Materials Science. 2008;53(6):893-979. doi:10.1016/j. pmatsci.2008.03.002

7. Rodríguez-Calvillo P, Ferrer N, Cabrera JM. Analysis of microstructure and strengthening in $\mathrm{CuMg}$ alloys deformed by equal channel angular pressing. Journal of Alloys and Compounds. 2015;626:340-348. doi:10.1016/j.jallcom.2014.12.043

8. Higuera-Cobos OF, Berríos-Ortiz JA, Cabrera JM. Texture and fatigue behavior of ultrafine grained copper produced by ECAP. Materials Science and Engineering: A. 2014; 609:273-282. doi:10.1016/j.msea.2014.05.011

9. Shokuhfar A, Nejadseyfi O. A comparison of the effects of severe plastic deformation and heat treatment on the tensile properties and impact toughness of aluminum alloy 6061 . Materials Science and Engineering: A. 2014;594:140-148. doi:10.1016/j.msea.2013.11.067

10. Ortiz-Cuellar E, Hernandez-Rodriguez MA, García-Sanchez E. Evaluation of the tribological properties of an $\mathrm{Al}-\mathrm{Mg}-\mathrm{Si}$ alloy processed by severe plastic deformation. Wear. 2011;271(910):1828-1832. doi:10.1016/j.wear.2010.12.082

11. Li J, Wongsa-Ngam J, Xu J, Shan D, Guo B, Langdon TG. Wear resistance of an ultrafine-grained $\mathrm{Cu}-\mathrm{Zr}$ alloy processed by equal-channel angular pressing. Wear. 2015;326-327:10-19. doi:10.1016/j.wear.2014.12.022

12. Zheng ZJ, Gao Y, Gui Y, Zhu M. Corrosion behaviour of nanocrystalline 304 stainless steel prepared by equal channel angular pressing. Corrosion Science. 2012;54(1):60-67. doi:10.1016/j.corsci.2011.08.049

13. Nejadseyfi O, Shokuhfar A, Dabiri A, Azimi A. Combining equal-channel angular pressing and heat treatment to obtain enhanced corrosion resistance in 6061 aluminum alloy. Journal of Alloys and Compounds. 2015;648:912-918. doi:10.1016/j. jallcom.2015.05.177

14. Myshlyaev MM, Mironov SY, Konovalova EV, Kamalov MM, Prokunin MA, Myshlyaeva MM. Structural state and superplasticity of an aluminum-lithium alloy subjected to equalchannel-angular pressing. The Phyaixa of Metals Metallography. 2006;102(3):328-332. DOI 10.1134/S0031918X06090146

15. Sakai G, Horita Z, Langdon TG. Grain refinement and superplasticity in an aluminum alloy processed by high-pressure torsion. Materials Science and Engineering: A. 2005;393(1-2):344351. doi:10.1016/j.msea.2004.11.007

16. Suh J, Victoria-Hernandez J, Letzig D, Golle R, Yi S, Bohlen J, Volk W. Improvement in cold formability of AZ31 magnesium alloy sheets processed by equal channel angular pressing. Journal of Materials Processing Technology. 2015;217:286293. doi:10.1016/j.jmatprotec.2014.11.029

17. Figueiredo R, Langdon T. Grain refinement and mechanical behavior of a magnesium alloy processed by ECAP. Journal of Material Science. 2010;45(17):4827-4836. DOI 10.1007/ s10853-010-4589-y

18. Nejadseyfi O, Shokuhfar A, Azimi A, Shamsborhan M. Improving homogeneity of ultrafine-grained/nanostructured materials produced by ECAP using a bevel-edge punch. Journal of Material Science. 2015;50(3):1513-1522. DOI 10.1007/ s10853-014-8712-3

19. Nejadseyfi O, Shokuhfar A, Sadeghi S, Dabiri A. Feasibility of attaining uniform grain structure and enhanced ductility in aluminum alloy by employing a beveled punch in Equal- channel angular pressing. Materials Science and Engineering: A. 2016;651:461. DOI: 10.1016/j.msea.2015.08.050

20. Wronski S, Tarasiuk J, Bacroix B, Wierzbanowski K, Paul H. Microstructure heterogeneity after the ECAP process and its influence on recrystallization in aluminium. Materials Characterization. 2013;78:60-68. doi:10.1016/j.matchar.2013.01.010

21. Agnew SR, Horton JA, Lillo TM, Brown DW. Enhanced ductility in strongly textured magnesium produced by equal channel angular processing. Scripta Materialia. 2004;50(3): 377-381. doi:10.1016/j.scriptamat.2003.10.006

22. Han WZ, Zhang ZF, Wu SD, Li SX, Wang YD. Anisotropic compressive properties of iron subjected to single-pass equalchannel angular pressing. Philosophical Magazine Letters. 2006;86(7):435-441.

23. Zhang X, Cheng Y. Tensile anisotropy of AZ91 magnesium alloy by equal channel angular processing. Journal of Alloys and Compounds. 2015;622:1105-1109. doi:10.1016/j. jallcom.2014.11.046

24. Hu HJ, Zhang DF, Pan FS. Die structure optimization of equal channel angular extrusion for AZ31 magnesium alloy based on finite element method. Transactions of Nonferrous Metals Society of China. 2010;20(2):259-266.

25. Si JY, Gao F, Zhang J. Finite element analysis of die geometry and process conditions effects on equal channel angular extrusion for $\beta$-titanium alloy. Journal of Iron and Steel Research International. 2012;19(10):54-58. DOI 10.1016/S1006-706X(12)60152-6

26. Kim HS. On the effect of acute angles on deformation homogeneity in equal channel angular pressing. Materials Science and Engineering: A. 2006;430(1-2):346-349. doi:10.1016/j. msea.2006.05.146

27. Jung J, Yoon S, Jun HJ, Kim H. Finite element analysis of deformation homogeneity during continuous and batch type equal channel angular pressing. Journal of Material Engineering and Performance. 2013;22(11):3222-3227. DOI 10.1007/ s11665-013-0632-x

28. Nejadseyfi O, Shokuhfar A, Moodi V. Segmentation of copper alloys processed by equal-channel angular pressing. Transactions of Nonferrous Metals Society of China. 2015;25(8):2571-2580. DOI: $10.1016 / \mathrm{S} 1003-6326(15) 63877-8$

29. Yamaguchi D, Horita Z, Nemoto M, Langdon TG. Significance of adiabatic heating in equal-channel angular pressing. Scripta Materialia. 1999;41(8):791-796. doi:10.1016/S13596462(99)00233-X

30. Vijayashakthivel AT, Srikantha Dath TN, Krishnamurthy R. Response of copper to Equal Channel Angular Pressing with different processing temperature. Procedia Engineering. 2014;97:56-63. doi:10.1016/j.proeng.2014.12.224

31. Wang YY, Sun PL, Kao PW, Chang CP. Effect of deformation temperature on the microstructure developed in commercial purity aluminum processed by equal channel angular extrusion. Scripta Materialia. 2004;50(5):613-617. doi:10.1016/j. scriptamat.2003.11.027

32. Nishida Y, Ando T, Nagase M, Lim SW, Shigematsu I, Watazu A. Billet temperature rise during equal-channel angular pressing. Scripta Materialia. 2002;46(3):211-216. doi:10.1016/S13596462(01)01226-X

33. Pei QX, Hu BH, Lu C, Wang YY. A finite element study of the temperature rise during equal channel angular pressing. Scripta Materialia. 2003;49(4):303-308. doi:10.1016/S13596462(03)00284-7

34. Jiang H, Fan Z, Xie C. Finite element analysis of temperature rise in CP-Ti during equal channel angular extrusion. Materials Science and Engineering: A. 2009;513-514:109-114. doi:10.1016/j. msea.2009.01.044 
35. Li M, Zhang C, Luo J, Fu M. Thermomechanical coupling simulation and experimental study in the isothermal ECAP processing of Ti-6Al-4V alloy. Rare Metals. 2010;29(6):613620. DOI 10.1007/s12598-010-0180-6

36. Kim HS. Finite element analysis of high pressure torsion processing. Journal of Materials Processing Technology. 2001;113(1-3):617-621. doi:10.1016/S0924-0136(01)00709-9

37. Shokuhfar A, Nejadseyfi O. The influence of friction on the processing of ultrafine-grained/nanostructured materials by equal-channel angular pressing. Journal of Matrials Engineering and Performance. 2014;23(3):1038-1048. DOI 10.1007/s11665013-0849-8
38. Semiatin SL, Berbon PB, Langdon TG. Deformation heating and its effect on grain size evolution during equal channel angular extrusion. Scripta Materialia. 2001;44(1):135-140. doi:10.1016/S1359-6462(00)00565-0

39. Quang P, Krishnaiah A, Hong SI, Kim HS. Coupled analysis of heat transfer and deformation in equal channel angular pressing of Al and steel. Materials Transactions. 2009; 50(1):40-43. DOI:10.2320/matertrans.MD200823

40. Pereira PH, Figueiredo RB, Huang Y, Cetlin PR, Langdon TG. Modeling the temperature rise in high-pressure torsion. Materials Science and Engineering: A. 2014;593:185-188. doi:10.1016/j.msea.2013.11.015 